https://helda.helsinki.fi

No effect of a parasite on reproduction in stickleback males : a laboratory artefact?

Candolin, U.

Cambridge University Press

2001

Parasitology (Cambridge)

http://hdl.handle.net/1975/146

Downloaded from Helda, University of Helsinki institutional repository.

This is an electronic reprint of the original article.

This reprint may differ from the original in pagination and typographic detail.

Please cite the original version. 


\title{
No effect of a parasite on reproduction in stickleback males: a laboratory artefact?
}

\author{
U. CANDOLIN ${ }^{1,2 *}$ and H.-R. VOIGT ${ }^{3}$ \\ ${ }^{1}$ Department of Biology, FIN-20014 University of Turku, Finland \\ ${ }^{2}$ School of Biological Sciences, University of East Anglia, Norwich NR4 7TF, UK \\ ${ }^{3}$ Department of Limnology and Environmental Protection, FIN-00014 University of Helsinki, Finland
}

(Received 19 September 2000; revised 2 November 2000; accepted 2 November 2000)

\begin{abstract}
S U M M A R Y
Experiments are often carried out in the laboratory under artificial conditions. Although this can control for confounding factors, it may eliminate important factors that under natural conditions mediate the interaction under investigation. Here, we show that different results can be gained in the field and in the laboratory regarding host-parasite interaction. In the field, courting three-spined stickleback males, Gasterosteus aculeatus, were less often infected with plerocercoids of a cestode tapeworm, Schistocephalus solidus, than shoaling males. However, when a random sample of males was allowed to nest and court females in individual aquaria in the laboratory, both uninfected and infected males built nests and courted females. Moreover, while the few infected males that courted females in the field expressed less red nuptial coloration than uninfected courting males, there was no difference in redness between infected and uninfected males in the laboratory. We argue that the different results gained in the field and in the laboratory are due to differences in the cost of reproduction, due to differences in the resource pool of the males. The favourable conditions in the laboratory exclude factors such as predation risk, social interactions, and fluctuating environmental conditions that may use up resources in the field and mediate the effect of the parasite.
\end{abstract}

Key words: host-parasite interaction, environmental effects, sexual signalling, Schistocephalus solidus, three-spined stickleback, Gasterosteus aculeatus.

\section{INTRODUCTION}

Researchers are often confined to do experiments in the laboratory, either because investigations are impossible to carry out in the field, or to eliminate confounding factors that may be difficult to control in the field. Although the importance of laboratory experiments in the investigation of interactions that occur in nature should not be underestimated, there is the possibility of artefacts because of laboratory conditions. Artificial laboratory conditions may impose new confounding factors, such as increased stress level, or important factors may be missing, such as resource limitation, that normally interact with the factor under investigation and determine the magnitude of its effect.

Divergent results have often been attained regarding the influence of parasites on reproduction (Read, 1988, 1990; Clayton, 1991; Sheldon \& Verhulst, 1996). These divergences can largely be accounted for by differences in parasite virulence and in genetically determined resistance of host populations. Another important factor that may cause divergent results is differences in environ-

* Corresponding author: School of Biological Sciences, University of East Anglia, Norwich NR4 7TJ, UK. Tel: +44 1603 593421. Fax: +44 1603592250 .

E-mail: u.candolin@uea.ac.uk mental conditions. Parasites often influence their hosts through the diversion of resources, either directly by using up energy and nutrients, or indirectly by increasing, for example, the activity of the immune system (Wedekind, 1992; Wedekind \& Folstad, 1994; Deerenberg et al. 1997) or by changing the behaviour and food intake of the host (Milinski, 1990). This means that a trade-off between the allocation of limiting resources to reproduction and to parasites and parasite resistance may occur. The influence of parasites on reproduction can then depend on the resource pool of the host, which in turn depends on environmental conditions. With no resource limitation there may be no effect of the parasite, whereas the effect of the parasite may increase with a decrease in resource availability. Environmental factors influence the resource pool by determining resource intake and the ability to replenish resources lost due to the parasite, and by influencing the amount of resources that have to be allocated to traits other than reproduction, such as predator vigilance and social interactions.

Laboratory conditions usually differ from field conditions and different results on the effect of parasites on reproduction may be obtained in the laboratory as compared to the field. Here, we compared the effect of plerocercoids of a cestode tapeworm, Schistocephalus solidus Muller, on re- 
production in three-spined stickleback males, Gasterosteus aculeatus L., in the field and in the laboratory. The parasite uses the stickleback as an intermediate host between copepods and the final host, piscivorous birds. It grows quickly in the body cavity and may eventually exceed the weight of the host (Arme \& Owen, 1967). It imposes metabolic demands on the host and several detrimental effects of the parasite have been recorded, including increased mortality (Threlfall, 1968; Walkey \& Meakins, 1970; Pennycuick, 1971 b), reduced swimming ability and greater vulnerability to predators (Arme \& Owen, 1967; Lester, 1971; LoBue \& Bell, 1993) and reduced female fecundity (Meakins, 1974). Divergent results have, however, been attained on the influence of the parasite on reproduction of males. Some studies have found infection to prevent male reproduction (Arme \& Owen, 1967; Pennycuick, 1971 $a$; Tierney, Huntingford \& Crompton, 1996) whereas others have not (McPhail $\&$ Peacock, 1983). The effect of the parasite on the expression of red carotenoid-based nuptial coloration, an important sexual signal (Milinski \& Bakker, 1990; Rowland, 1994), is especially unclear. According to the indicator mechanism, sexually selected traits may reveal parasite resistance or the ability to sustain infection (Hamilton \& Zuk, 1982; Andersson, 1994), both of which could indicate genetic and/or phenotypic quality of the male. However, while some studies find infected stickleback males to be less bright than uninfected ones (Pennycuick, 1971b; Folstad et al. 1994) others do not (Arme \& Owen, 1967; Tierney et al. 1996). The same contradictory results have also been found for other parasite species (Jamieson, 1994). In this paper we show that the relationship between $S$. solidus infection and reproduction can vary within a stickleback population depending on environmental conditions. Under laboratory conditions the parasite did not prevent reproduction whereas few infected males courted females in the field. We argue that this discrepancy is due to the favourable conditions in the laboratory that exclude factors such as predation risk, social interactions, and fluctuating environmental conditions that use up resources in the field and probably mediate the effect of the parasite.

\section{MATERIALS AND METHODS}

\section{Field study}

Courting males. We caught 35 males from a shallow bay (max. depth $1.5 \mathrm{~m}$ ) in the archipelago near Tvärminne Zoological Station in southern Finland $\left(60^{\circ} \mathrm{N}, 23^{\circ} \mathrm{E}\right)$ between 1 and 9 June in 1997 by hand-netting the males individually. All males had nests at depths of $30-60 \mathrm{~cm}$ and were in the courtship phase when caught. The bay is a preferred breeding area with a high density of courting males and gravid females during the breeding season (up to 5 territorial males $/ \mathrm{m}^{2}$ ). Immediately following capture, we photographed the left lateral side of the male under standardized conditions in a box containing a digital camera (see Candolin (1999b) for details). The male was enclosed in a small glass box $(6 \times 3 \times 6 \mathrm{~cm})$ that was placed in fixed position in the larger box. The only light source was a lateral flash. We determined the extent and quality of the red nuptial coloration from the digital images using image analysis software (MCID-M4, Imaging research Inc., Brock University, St Catharines, Ontario, see Candolin (1999b). We selected areas that ranged in colour from yellow over red to purple (hue: $1-50$ and 340-359, saturation (chroma). 0-0.631, intensity (brightness): 0.157-0.663), and recorded their size and mean colour hue, saturation and intensity. We used a tristimulus system constructed to fit the human eye as colour vision of sticklebacks does not differ greatly from that of humans (reviewed by Frischknecht, 1993; McKinnon, 1995). The size of the red areas is given as the percentage of the total areas of the photographed males.

We humanely killed the males with anaesthetics (MS 222) immediately after photography and brought them to the laboratory. We measured their standard lengths to the nearest $\mathrm{mm}$ and then separated any $S$. solidus from the fish and dried the fish and the parasite for $24 \mathrm{~h}$ at $60{ }^{\circ} \mathrm{C}$ to determine their dry weights. We determined the lipid content of the fish by the Soxhlet method by dissolving the fat in petroleum ether until the fish attained a constant dry weight (Reznick \& Braun, 1987). Three lipid extractions, each lasting for $5 \mathrm{~h}$, were required. Lipid content was estimated as the percentage of dry weight lost.

Shoaling males. We caught shoals of sticklebacks with Plexiglas-traps from the same area as mentioned above both before the breeding season, when they had just arrived in the bay (1-12 May 1997), and during the breeding season when large shoals of males and females swam around the bay (1-9 June 1997). The traps, $20 \times 20 \times 40 \mathrm{~cm}$, had wings, $20 \times 60 \mathrm{~cm}$, that directed fish towards the opening of the trap, $1.5 \times 20 \mathrm{~cm}$. No selectivity of the traps in relation to $S$. solidus infection or size of adult fish (over $45 \mathrm{~mm}$ ) has been found when the catch of fish from traps has been compared to that by seining (Candolin, unpublished data). A few courting males were caught in the traps during the breeding season, but they were easily separated from shoaling males by their red nuptial coloration and excluded from the analyses. Juveniles were released back to the sea and only fish over $45 \mathrm{~mm}$ in standard length were brought to the laboratory, as fish under $45 \mathrm{~mm}$ 
usually do not breed in this population (Candolin, personal observation). We separated a random sample of the shoaling fish caught before the breeding season for the experiment described below. The rest of the fish were dissected for the determination of sex and infection with $S$. solidus. We dissected 50 shoaling males caught before the breeding season and 48 males caught during the breeding season.

\section{Laboratory study}

Males caught before the breeding season. Nonbreeding males and females cannot be separated and we therefore stimulated maturation by housing the fish in holding aquaria for 1 week at $18^{\circ} \mathrm{C}$ under a 18:6 h light: dark cycle at a density of 10 fish per 125 litre aquarium. We fed them once a day frozen chironomid larvae in excess. Fish that were females, as determined by their coloration and developed ovaries, were moved to separate holding aquaria where they were fed frozen chironomid larvae and wild-caught invertebrates several times a day to ensure a constant supply of gravid females. We allowed the remaining fish, of which most had blue eyes and thus were males, to nest singly in aquaria $(35 \times 45 \mathrm{~cm}$, water height $30 \mathrm{~cm})$. Each aquarium contained a nesting dish (14 $\mathrm{cm}$ in diameter) filled with $1 \mathrm{~cm}$ of sand, an artificial plant, and some Cladophora as nesting material. White curtains with small viewing holes reduced external disturbances. We restricted the food intake of the males to 5 chironomid larvae a day, which is much less than the fish ate when fed ad libitum.

To stimulate nest building, we exposed each male to a gravid female enclosed in a Plexiglass cylinder $(10 \mathrm{~cm}$ in diameter) for $2 \mathrm{~min}$ twice a day. We recorded the number of days it took before a male had built a nest and crept through it. Fish that did not start to build a nest within 14 days were removed from further experimentation and dissected for the determination of sex and infection with S. solidus. We determined male courtship behaviour and red colour expression the day after nest completion by presenting the male to a gravid female enclosed in the Plexiglass cylinder. The number of leads to the nest and the total time spent courting (see Candolin (1997) for details) were recorded during $10 \mathrm{~min}$ of female exposure. Red coloration was determined immediately afterwards by dipnetting the male and photographing him as described above. In the population, the frequency of leads (whereby the male attempts to lead a female to the nest), and not zigzag movements, has been found to reflect male courtship intensity and attractiveness to females (Candolin, 1997).

The next day we put a gravid female into the aquarium and allowed her to spawn in the male's nest. If the female did not spawn within $1 \mathrm{~h}$, she was replaced by a new female. We removed the female immediately after spawning and determined the amount of eggs spawned both by recording female wet weight before and after spawning, and by weighing the eggs 3-4 h after spawning when the egg mass had hardened (see Candolin (2000) for details). The 2 measures of egg mass were highly correlated $(r$ $=0.93, n=40, P<0.0001)$ and we therefore used the latter, direct measure of egg quantity in the analyses.

The male was left to care for the eggs and 8 days later, when the eggs were almost ready to hatch, we determined the reproductive success of the male. We removed dead and undeveloped eggs and weighed the remaining eggs to determine the percentage of the eggs that had survived. Developed, healthy eggs were easily separated from dead eggs by the dark embryo moving inside the chorion. Under the conditions, the eggs would have hatched on day 9 or 10 and the number of developed, healthy eggs present at day 8 correlates with the number of eggs hatching when a male is allowed to continue to care for the eggs until hatching (Candolin, unpublished data). The weight of an egg does not change much during development, and the changes that occur do not differ over replicates. Male standard body length, dry weight, lipid content and infection by $S$. solidus were determined after the experiment.

Since the fish were caught on different days, they were also transferred to the experimental aquaria on different days. To control for this, we blocked the analyses by date. However, there was no significant effect of date $(P>0 \cdot 2)$ and the statistical analyses with and without block design yielded the same results. We therefore report statistical values only for analyses without blocks.

Males caught during the breeding season. To investigate whether the infected males that were shoaling during the breeding season would court females if transferred to the laboratory, we allowed 14 heavily infected shoaling males caught from the bay in the beginning of June to nest in aquaria under the same conditions as described above. Heavily infected males were easily identified by their extended bellies.

\section{RESULTS}

In the field the proportion of infected males was significantly lower among courting males than among shoaling males, both in relation to males shoaling before the breeding season and males shoaling during the season (Table $1 \mathrm{~A}$ ). If the males used in the laboratory experiment are included in the number of males caught before the season, 23 of 90 males $(25.6 \%)$ were infected. In the laboratory, in 
Table 1. Number of uninfected and infected males in the field (A) and in the laboratory (B)

( $P$ values from two-tailed Fisher's exact test are given. Shoaling males caught before the breeding season are tested against courting males caught during the season.)

\begin{tabular}{|c|c|c|c|c|c|}
\hline \multirow{2}{*}{$\begin{array}{l}\text { (A) } \\
\text { Field study }\end{array}$} & \multicolumn{2}{|c|}{ Shoaling males } & \multicolumn{2}{|c|}{ Courting males } & \multirow[b]{2}{*}{$P$} \\
\hline & Uninfected & Infected ( $\%)$ & Uninfected & Infected $(\%)$ & \\
\hline \multicolumn{6}{|l|}{ Caught } \\
\hline Before season & 38 & $12(24)$ & & & $0 \cdot 036$ \\
\hline During season & 33 & $15(32)$ & 33 & $2(6)$ & $0 \cdot 005$ \\
\hline \multirow{2}{*}{ (B) } & \multicolumn{2}{|c|}{ Non-reproducing males } & \multicolumn{2}{|c|}{ Courting males } & \\
\hline & Uninfected & Infected $(\%)$ & Uninfected & Infected $(\%)$ & $P$ \\
\hline Laboratory males & 3 & $1(25)$ & 26 & $10(28)$ & $1 \cdot 00$ \\
\hline
\end{tabular}

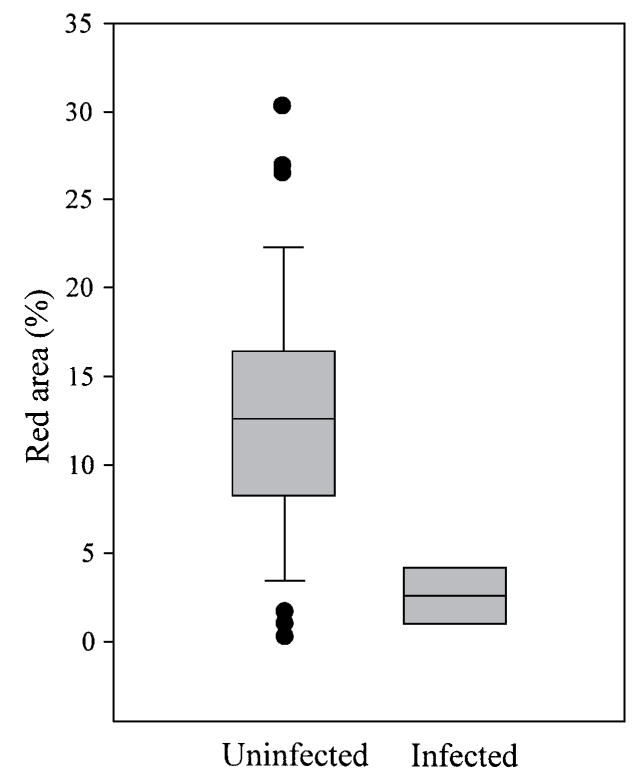

Fig. 1. Box plot of red area of uninfected and infected males courting females in the field. The median, 10th, 25 th, 75 th and 90 th percentiles and outliers are shown.

contrast, both infected and uninfected males nested and courted females (Table $1 \mathrm{~B}$, the power to find a difference of the same size as in the field is 0.49 with a chi-square test and $\alpha=0.05$ (Cohen, 1988)), and the proportion of courting males that were infected was higher than in the field (Fisher's exact test: $P=$ $0 \cdot 024)$. Moreover, 11 of the 14 infected nonreproducing males brought to the laboratory from the field during the breeding season built nests and courted females within 1 week. This differs from the proportion of infected males courting females in the field ( 2 out of 17, Fisher's exact test: $P=0 \cdot 0003$ ). Infected males in shoals are consequently capable of courting females. Thus, it appears to be the environment that determines whether an infected male will court females or not.

In the field, the 2 infected courting males were less colourful than the 33 uninfected courting males as they had smaller red areas (means \pm s.e. $=2 \cdot 6 \pm 1 \cdot 6 \%$ and $12 \cdot 6 \pm 1 \cdot 3 \%$, respectively, Mann-Whitney $U$ test; $U=61, P=0 \cdot 047$, Fig. 1) but their colour quality was the same (hue: $U=18, \quad P=0 \cdot 29$, saturation: $U=37, P=0 \cdot 77$, intensity: $U=50, P$ $=0 \cdot 21)$. In the laboratory, there was no difference in either red area or colour quality between infected and uninfected males (Table 2, the power of the test to detect a difference in red area of the same magnitude as in the field, $10 \%$, is 0.95 with $\alpha=$ $0 \cdot 05)$. No correlation was found between red area and parasite index (the proportion of the dry weight of the male that is contributed by parasite tissue) but the power of the test is only $0 \cdot 22(r=-0 \cdot 30, n=10$, $P=0 \cdot 41$, the mean \pm s.E. parasite index of the infected fish being $26 \cdot 8 \pm 1 \cdot 3 \%$ ). Neither was there a difference between infected and uninfected males in courtship activity or in the time it took to build a nest (Table 2, the power of the test to detect a moderate effect size is 0.37 with $\alpha=0.05$ (Cohen, 1988)). However, infected males had a lower hatching success than uninfected males, with the proviso that the difference is not significant if sequential Bonferroni correction is applied to the table (Rice, 1989).

Infected males were in poorer condition than uninfected males in the laboratory as they had a lower dry weight when the weight of the parasite was subtracted, and a lower lipid content (Table 2). There was no difference in length (standard) between infected and uninfected fish (Table 2). In contrast, infected courting males in the field had a marginally higher dry weight than uninfected courting males when the weight of the parasite was subtracted (mean \pm s.e. dry weight of uninfected: $0.473 \pm$ $0.015 \mathrm{~g}$, infected: $0.547 \pm 0.002 \mathrm{~g}$, Mann-Whitney $U$-test, $U=8, P=0 \cdot 076$, Fig. 2). No differences in standard length (uninfected: $51.5 \pm 0.5 \mathrm{~mm}$, infected: $52.5 \pm 0.5 \mathrm{~mm}, U=22, P=0.45)$ or in lipid content were found (uninfected: $16 \cdot 88 \pm 1 \cdot 33 \%$, infected: $11 \cdot 15 \pm 1 \cdot 82 \%, U=49, P=0 \cdot 26)$, with the constraint that only 2 infected courting males were caught. The 2 infected courting males in the field 
Table 2. Secondary sexual traits, nest building time, hatching success and body characteristics of uninfected and infected males caught before the breeding season and allowed to breed in the laboratory.

(Means \pm s.E. are given. ANOVA, and MANOVA were used for analyses.)

\begin{tabular}{|c|c|c|c|c|}
\hline & $\begin{array}{l}\text { Uninfected } \\
(n=26)\end{array}$ & $\begin{array}{l}\text { Infected } \\
(n=10)\end{array}$ & $F_{1,33}$ & $P$ \\
\hline Red area $(\%)$ & $15 \cdot 9 \pm 1 \cdot 5$ & $15 \cdot 7 \pm 2 \cdot 9$ & $0 \cdot 002$ & $0 \cdot 961$ \\
\hline \multicolumn{5}{|l|}{ Red colour quality } \\
\hline Hue & $95 \cdot 4 \pm 6 \cdot 3$ & $93 \cdot 7 \pm 6 \cdot 2$ & $0 \cdot 025$ & $0 \cdot 874$ \\
\hline Saturation & $0 \cdot 111 \pm 0 \cdot 006$ & $0 \cdot 094 \pm 0 \cdot 007$ & $2 \cdot 59$ & $0 \cdot 117$ \\
\hline Intensity & $0 \cdot 460 \pm 0 \cdot 015$ & $0 \cdot 428 \pm 0 \cdot 017$ & $1 \cdot 43$ & $0 \cdot 240$ \\
\hline \multicolumn{5}{|c|}{ MANOVA: Wilks' $\lambda=0.853, F=1 \cdot 84$, D.F. $=3 \cdot 32, P=0.16$} \\
\hline \multicolumn{5}{|l|}{ Courtship activity } \\
\hline Number of leads & $73 \cdot 0 \pm 6 \cdot 0$ & $54 \cdot 9 \pm 10 \cdot 5$ & $2 \cdot 42$ & $0 \cdot 129$ \\
\hline Time courting (s) & $596 \cdot 9 \pm 3 \cdot 1$ & $590 \cdot 0 \pm 6 \cdot 8$ & $1 \cdot 14$ & $0 \cdot 294$ \\
\hline Days until nest completion & $3 \cdot 4 \pm 0 \cdot 4$ & $2 \cdot 8 \pm 0 \cdot 4$ & $0 \cdot 62$ & $0 \cdot 437$ \\
\hline Hatching success $(\%)$ & $64 \cdot 0 \pm 6 \cdot 1$ & $32 \cdot 9 \pm 14 \cdot 0$ & $5 \cdot 69$ & $0 \cdot 023$ \\
\hline Body length $(\mathrm{mm})$ & $53 \cdot 3 \pm 0 \cdot 5$ & $53 \cdot 1 \pm 0 \cdot 8$ & $0 \cdot 08$ & $0 \cdot 784$ \\
\hline Dry weight (g, exc. parasites) & $0 \cdot 43 \pm 0 \cdot 01$ & $0 \cdot 33 \pm 0 \cdot 02$ & $14 \cdot 39$ & $0 \cdot 001$ \\
\hline Lipid content $(\%)$ & $15 \cdot 0 \pm 1 \cdot 4$ & $7 \cdot 5 \pm 1 \cdot 2$ & $9 \cdot 92$ & $0 \cdot 003$ \\
\hline
\end{tabular}

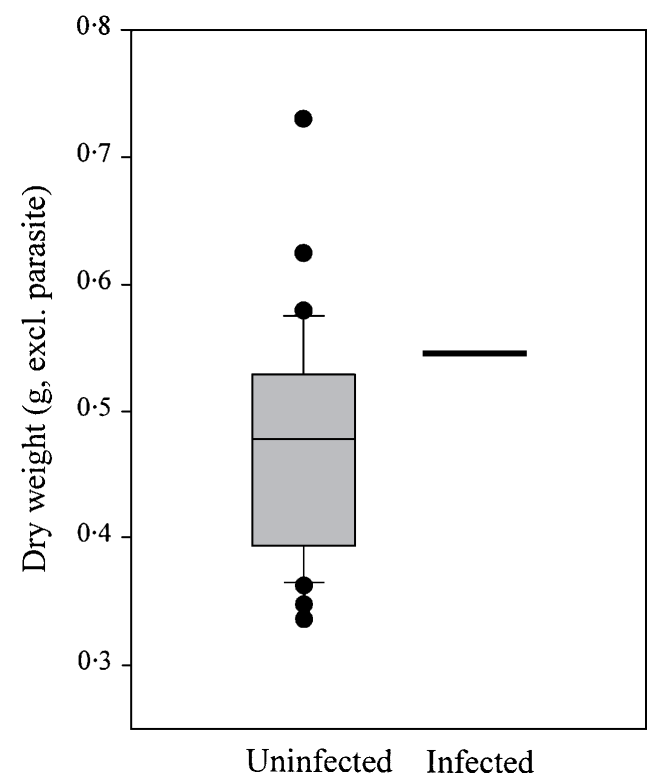

Fig. 2. Box plot of dry weight (exc. parasite) of uninfected and infected males courting females in the field. The median, 10th, 25 th, 75 th and 90 th percentiles and outliers are shown.

had a lower parasite index than the infected shoaling males (courting: $17 \cdot 7 \pm 2 \cdot 4 \%$ and shoaling: $27 \cdot 6 \pm$ $1.2 \%, U=0, P=0.025)$ and a higher dry weight when the weight of the parasite was excluded (courting: 0.547 $\pm 0 \cdot 002 \mathrm{~g}$, shoaling: 0.334 $\pm 0 \cdot 014 \mathrm{~g}$, $U=0, P=0.025)$. Thus, of the infected males in the field, only the largest males with the lowest parasite index courted females.

The mean parasite index of the 10 infected courting males in the laboratory was $26 \cdot 8 \pm 1 \cdot 3 \%$ (s.E.) and that of the non-reproducing male was $19.7 \%$. The parasite index of the 14 heavily infected males brought to the laboratory was $35 \cdot 2 \pm 1 \cdot 7 \%$.
Among these 14 fish, there was no significant difference in parasite index between the 11 males that reproduced in the laboratory $(34.7 \pm 2.1 \%)$ and the 3 males that did not $(37 \cdot 1 \pm 1 \cdot 4 \%, U=17, P=$ 0.94).

\section{DISCUSSION}

In the field the rate of infection with $S$. solidus was lower among courting males than among shoaling non-reproducing males. In the laboratory, infected males readily built nests, developed red nuptial coloration, and courted females. The different results gained in the field and in the laboratory are highly unlikely to be due to the sampling of different subpopulations, with a lower infection rate in the field population than in the laboratory population, as the laboratory males were collected from the same site as the field males. Neither was there a spatial difference in the distribution of nesting infected and uninfected males in the field.

Whether the low frequency of infected males courting females in the field is due to infection preventing males from building nests and courting females in this area, or whether infected males performed less courtship and were less conspicuous and therefore were less often caught by us is not known. The high frequency of infected males in shoals suggests that most infected males remained in shoals during the breeding season. It is possible that they adopted an energetically less costly reproductive strategy, sneak fertilization, whereby the sneaker observes a courting pair and then tries to creep through the nest and fertilize the eggs before the nest owner (Assem, 1967; Kynard, 1978). Whichever is the case, infection most likely reduces reproductive 
success in the field as few sneak attempts are successful (Goldschmidt, Foster \& Sevenster, 1992) and reduced courtship reduces attractiveness and encounters with females (Candolin, 1997).

The result that infected non-reproducing males built nests and courted females when transferred to the laboratory suggests that environmental conditions mediated the effect of the parasite on reproduction. Since reproduction is energetically costly (Chellappa et al. 1989; FitzGerald, Guderley \& Picard, 1989) and the parasite imposes large energetic demands on the host (Walkey \& Meakins, 1970), it seems likely that environmental conditions mediated the effect of the parasites by determining the resource pool of the male and thus the cost of reproduction. In the field, reproduction is probably much more expensive than under the present laboratory conditions, as males have to establish a territory under male-male competition and defend it against both competing males that try to occupy it and shoals of conspecifics that try to raid the nest to eat the eggs. In addition predation pressure is high in the study bay, especially from terns, and predator vigilance may be expensive by using up resources or altering feeding behaviour and thus reducing food intake. Furthermore, fluctuating environmental conditions such as temperature and oxygen levels in the field may increase the stress level. An infected male in the field with a low resource pool due to the energetic demands of the parasite may not have enough resources available for adopting the courtship strategy after paying all of these costs. In the laboratory, in contrast, no male-male interactions or predation threat occurred, the environmental conditions were constant and males were provided with a constant, although low supply of food. Even an infected male may then have had enough resources for reproduction and no effect of the parasite on courtship may therefore have occurred.

The lack of an effect of the parasite on red coloration in the laboratory, whereas infected males in the field were less colourful than uninfected males, is especially interesting. Since infected males had a lower hatching success than uninfected males, this means that red coloration did not reflect male parental ability under the laboratory conditions and was consequently not an honest indicator of mate quality in the laboratory. Honest signalling is assumed to be assured by the cost of signalling with low quality males not being able to afford signals as costly as those of high quality males (Zahavi, 1975; Grafen, 1990). This implies that the cost of signalling was not high enough in the laboratory to prevent dishonest signalling from occurring. Carotenoidbased colours have been suggested to be costly because of a trade-off between the allocation of carotenoids to the ornament and to the immune system (Lozano, 1994, but see Hill, 1999), and by the immunosuppressive effect of androgens that are responsible for the expression of the colour (Folstad \& Karter, 1992). For this to work in this study, infected laboratory males must have had a less active immune system or a larger pool of carotenoids than infected males in the field. Although these possibilities cannot be ruled out, it seems more likely that the environmental conditions mediated the effect of the parasite on ornamentation by influencing the resource pool of the males and thus the fitness cost of ornamentation, in the same way as argued above. Red coloration is costly because it increases the risk of predation (Moodie, 1972; Whoriskey \& FitzGerald, 1985) and the risk of fights with competing males (Bakker, 1994). It is adjusted to the appearance of predators (Candolin, 1998, 1999 b) and rivalling males (Candolin, 1999a) and so the availability of carotenoids is not the only determinant of red colour expression. Social interactions may be expensive in the field and males with small resource pools due to infection may express less red coloration than uninfected males with larger resource pools to avoid fights with superior males. In the laboratory, no male-male competition occurred and signalling was probably less costly. Even an infected male may then have had enough resources to express red coloration. The degree of ornamentation may then have depended more on the availability of carotenoids, which may not have differed between infected and uninfected males.

The importance of the resource pool of the male in determining whether a parasite will prevent courtship or not is further supported by the result that the few infected males that courted females in the field were in good condition, as judged by their dry weight. This is in accordance with the results of Tierney et al. (1996) and suggests that only good condition males can pay the cost of both infection and reproduction. In the laboratory, on the other hand, no relationship between infection, body condition and reproduction was found, suggesting that favourable conditions may also allow poor condition males to reproduce. This may decrease the intensity of parasite-mediated sexual selection, which points to the role of resource limitation in the evolution and maintenance of adaptive mating systems.

In conclusion, this study shows that different results on the effect of a parasite on reproduction can be attained in the laboratory and in the field. This is probably due to differences in the environmental conditions that determine the resource pool of the male and thus mediate the effect of infection on reproduction. Caution should therefore be taken when interpreting results from the laboratory or other unnatural conditions.

We thank Sarah Kraak and Manfred Milinski for valuable comments on the paper. The research was supported by grants to UC from the Academy of Finland, the Section of Ecology at University of Turku, and Ella and Georg Ehrnrooth Foundation. 


\section{REFERENCES}

Andersson, M. (1994). Sexual Selection. Princeton University Press, Princeton.

ARME, C. \& OWEN, R. W. (1967). Infections of the threespined stickeback, Gasterosteus aculeatus L., with the plerocercoid larvae of Schistocephalus solidus (Muller, 1776) with special reference to pathological effects. Parasitology 57, 301-314.

ASSEM, J. VAN DEN. (1967). Territoriality in the threespine stickleback, Gasterosteus aculeatus L.: an experimental study in intra-specific competition. Behaviour 16 (Suppl.), 1-164.

BAKKER, T. C. M. (1994). Evolution of aggressive behaviour in the threespine stickleback. In The Evolutionary Biology of the Threespine Stickleback (ed. Bell, M. A. \& Foster, S. A.), pp. 345-380. Oxford University Press, Oxford.

CANDolin, U. (1997). Predation risk affects courtship and attractiveness of competing threespine stickleback males. Behavioral Ecology and Sociobiology 41, 81-87.

CANDOlin, U. (1998). Reproduction under predation risk and the trade-off between current and future reproduction in the threespine stickleback. Proceedings of the Royal Society of London, B 265, 1171-1175.

CANDOLIN, U. (1999a). Male-male competition facilitates female choice in sticklebacks. Proceedings of the Royal Society of London, B 266, 785-789.

CANDOLin, U. (1999b). The relationship between signal quality and physical condition: is sexual signalling honest in the three-spined stickleback? Animal Behaviour 58, 1261-1267.

CANDOLIN, U. (2000). Increased signalling effort when survival prospects decrease: male-male competition ensures honesty. Animal Behaviour 60, 417-422.

CHELlappa, S., HUNTINGFORD, F. A., STRANG, R. H. C. \& THOMPSON, R. Y. (1989). Annual variation in energy reserves in male three-spined stickleback, Gasterosteus aculeatus L. (Pisces, Gasterosteidae). Fournal of Fish Biology 35, 275-286.

Clayton, D. H. (1991). The influence of parasites on host sexual selection. Parasitology Today 7, 329-334.

CoHen, J. (1988). Statistical Power Analysis for the Behavioral Sciences. Lawrence Erlbaum Associates, Hillsdale, New Jersey.

DEERENBERG, C., APANiUs, V., DAAN, s. \& BOS, N. (1997). Reproductive effort decreases antibody responsiveness. Proceedings of the Royal Society of London, B 264, 1021-1029.

FitZGERALD, G. J., GUDERLEy, H. \& PICARD, P. (1989). Hidden reproductive costs in the three-spined stickleback (Gasterosteus aculeatus). Experimental Biology 48, 295-300.

FOLSTAD, I., HOPE, A. M., KARTER, A. \& SKORPING, A. (1994). Sexually selected color in male sticklebacks: a signal of both parasite exposure and parasite resistance? Oikos 69, 511-515.

FOLSTAD, I. \& KARTER, A. J. (1992). Parasites, bright males and the immunocompetence handicap. American Naturalist 139, 603-622.

FRISCHKNECHT, M. (1993). The breeding colouration of male three-spined sticklebacks (Gasterosteus aculeatus) as an indicator of energy investment in vigour. Evolutionary Ecology 7, 439-450.
GOLDSCHMidT, T., FOSTER, S. A. \& SEVENSTER, P. (1992). Internest distance and sneaking in three-spined stickleback. Animal Behaviour 44, 793-795.

GRAFEN, A. (1990). Biological signals as handicaps. Fournal of Theoretical Biology 144, 517-546.

HAMilton, w. D. \& ZUK, M. (1982). Heritable true fitness and bright birds: a role for parasites? Science $\mathbf{2 1 8}$, 384-387.

HILL, G. E. (1999). Is there an immunological cost to carotenoid-based ornamental coloration? American Naturalist 154, 589-595.

JAMIESON, I. G. (1994). The evolution of conspicuous coloration in male three-spined sticklebacks: Contradictory results and conflicting studies. Ecoscience 1, 281-284.

KYNARD, B. E. (1978). Breeding behavior of a lacustrine population of threespine sticklebacks (Gasterosteus aculeatus L.) Behaviour 67, 178-207.

LESTER, R. J. G. (1971). The influence of Schistocephalus plerocercoids on the respiration of Gasterosteus and a possible resulting effect on the behaviour of the fish. Canadian Fournal of Zoology 49, 361-366.

LOBue, C. P. \& BELL, M. A. (1993). Phenotypic manipulation by the cestode parasite Schistocephalus solidus of its intermediate host, Gasterosteus aculeatus, the threespine stickleback. American Naturalist 142, 725-735.

LOZANO, G. A. (1994). Carotenoids, parasites, and sexual selection. Oikos 70, 309-311.

MCKINNON, J. s. (1995). Video mate preferences of female three-spined sticklebacks from populations with divergent male coloration. Animal Behaviour 50, 1645-1655.

McPhail, J. D. \& PEACOCK, S. D. (1983). Some effects of the cestode (Schistocephalus solidus) on reproduction in the threespine stickleback (Gasterosteus aculeatus): evolutionary aspects of a host-parasite interaction. Canadian fournal of Zoology 61, 901-908.

MEAKINS, R. H. (1974). A quantitative approach to the effects of the plerocercoid of Schistocephalus solidus Müller 1776 (Pseudophylidae) on the ovarian maturation of the three-spined stickleback Gasterosteus aculeatus L. Zeitschrift für Parasitenkunde 44, 73-79.

Milinski, M. (1990). Parasites and host decision-making. In Parasitism and Host Behaviour (ed. Barnard, C. J. \& Behnke, J. M.), pp. 95-116. Taylor and Francis, London.

MiLINSKi, M. \& BAKKeR, T. C. M. (1990). Female sticklebacks use male coloration in mate choice and hence avoid parasitized males. Nature, London 344, 330-333.

MOODIE, G. E. E. (1972). Predation, natural selection and adaptation in an unusual threespine stickleback. Heredity 28, 155-167.

PENNYCUICK, L. (1971 a). Differences in the parasite infection in three-spined sticklebacks (Gasterosteus aculeatus L.) of different sex, age, and size.

Parasitology 63, 407-418.

PENNYCuICK, L. (1971 $b$ ). Quantitative effects of three species of parasites on a population of three-spined sticklebacks, Gasterosteus aculeatus L. Fournal of Zoology 165, 143-162.

READ, A. F. (1988). Sexual selection and the role of parasites. Trends in Ecology and Evolution 3, 97-102. 
READ, A. F. (1990). Parasites and host sexual behaviour. In Parasitism and Host Behaviour (ed. Barnard, C. J. \& Behnke, J. M.), pp. 117-157. Taylor and Francis, London.

REZNICK, D. N. \& BRAUN, B. (1987). Fat cycling in the mosquitofish (Gambusia affinis): fat storage as a reproductive adaptation. Oecologia 73, 401-413.

RICE, W. R. (1989). Analyzing tables of statistical test. Evolution 43, 223-225.

RoWland, W. J. (1994). Proximate determinants of stickleback behaviour: an evolutionary perspective. In The Evolutionary Biology of the Three-spine Stickleback (ed. Bell, M. A. \& Foster, S. A.), pp. 297-344. Oxford University Press, Oxford.

SHELDON, B. C. \& VERHULST, s. (1996). Ecological immunology and trade-offs in evolutionary ecology. Trends in Ecology and Evolution 11, 317-321.

Threlfall, w. (1968). A mass die-off of threespined sticklebacks (Gasterosteus aculeatus L.). Canadian Fournal of Zoology 46, 105-106.
TIERNEY, J. F., HUNTINGFORD, F. A. \& CROMPTON, D. W. T. (1996). Body condition and reproductive status in sticklebacks exposed to a single wave of Schistocephalus solidus infection. Fournal of Fish Biology 49, 483-493.

WALKEY, M. \& MEAKINS, R. H. (1970). An attempt to balance the energy budget of a host-parasite system. Fournal of Fish Biology 2, 361-372.

WEDEKIND, C. (1992). Detailed information about parasites revealed by sexual ornamentation. Proceedings of the Royal Society of London, B 247, 169-174.

WEDEKind, C. \& FOlstad, I. (1994). Adaptive or nonadaptive immunosuppression by sex hormones? American Naturalist 143, 936-938.

WHORiskey, F. G. \& FITZGERALD, G. J. (1985). The effects of bird predation on an estuarine stickleback (Pisces: Gasterosteidae) community. Canadian Fournal of Zoology 63, 301-307.

ZAHAVI, A. (1975). Mate selection-a selection for a handicap. Fournal of Theoretical Biology 53, 205-214. 